\title{
Expression of HCLCA1 in cystic fibrosis lungs is associated with mucus overproduction
}

\author{
H.P. Hauber*, A. Tsicopoulos\#, B. Wallaert*, S. Griffin ${ }^{\Uparrow}$, N.G. McElvaney», P. Daigneault*, Z. Mueller*, \\ R. Olivenstein ${ }^{+}$, K.J. Holroyd ${ }^{\S}$, R.C. Levitt ${ }^{\S}$, Q. Hamid*
}

Expression of HCLCA1 in cystic fibrosis lungs is associated with mucus overproduction. H.P. Hauber, A. Tsicopoulos, B. Wallaert, S. Griffin, N.G. McElvaney, P. Daigneault, Z. Mueller, R. Olivenstein, K.J. Holroyd, R.C. Levitt, Q. Hamid. (C) ERS Journals Ltd 2004.

ABSTRACT: Mucus overproduction is typical in cystic fibrosis (CF) airway disease. The human calcium-activated chloride channel, hCLCA1, has been reported to be upregulated by interleukin (IL)-9 and to regulate the expression of mucins. Therefore, the expression of IL-9, IL-9 receptor (IL-9R) and hCLCA1 between the lungs of CF patients and healthy control subjects was compared.

Endoscopic biopsy samples of bronchial mucosa from $10 \mathrm{CF}$ patients and six control subjects were stained with periodic acid-Schiff. IL-9, IL-9R and hCLCA1 expression was determined by immunocytochemistry. Expression of hCLCA1 mRNA was also determined by in situ hybridisation.

The present study found significant increases in IL-9, IL-9R and hCLCA1 immunoreactivity, hCLCA1 mRNA expression, and numbers of mucus-producing cells in the mucosa of $\mathrm{CF}$ patients compared to control subjects. Positive correlations were found between IL-9R-positive-cells with IL-9-positive cells and hCLCA1-positive cells, and between PAS-positive cells with hCLCA1-positive cells and IL-9R-positive cells. Expression of hCLCA1 mRNA was colocalised with IL-9R expression and PAS-positive staining in epithelial cells.

Increased expression of interleukin-9 and interleukin-9 receptor, as well as an upregulation of the human calcium-activated chloride channel, hCLCA1, in mucus-producing epithelium of cystic fibrosis patients, support the hypothesis that interleukin-9 contributes to mucus overproduction in cystic fibrosis airway disease. Eur Respir J 2004; 23: 846-850.
*Meakins-Christie Laboratories, McGill University, Montreal, Canada. ${ }^{\#}$ U416 INSERM, Institut Pasteur de Lille and Centre de Soins Mucoviscidose Adulte, Hôpital Calmatte, Lille, France. Royal College of Surgeons, Dublin, Ireland. ${ }^{+}$Montreal Chest Hospital, Montreal, Canada. ${ }^{\S}$ Genaera Corporation, Plymouth Meeting, PA, USA.

Correspondence: Q. Hamid, Meakins-Christie Laboratories, 3626 St-Urbain Street, Montreal, Quebec, H2X 2P2, Canada.

Fax: 15143987483

E-mail: qutayba.hamid@mcgill.ca

Keywords: Cystic fibrosis

hCLCA1

interleukin-9

mucus

Received: August 222003

Accepted after revision: December 172003

This work was supported by the Genaera Corporation and the Canadian Institutes of Health Research, Canada. H.P. Hauber is the recipient of a grant from the ChristianeHerzog Stiftung.
Excess mucus production is a hallmark of cystic fibrosis (CF) lung disease. Previous reports have shown that neutrophil elastase is a potent mucus secretagogue [1,2] and that lipopolysaccharide from Pseudomonas aeruginosa can directly induce upregulation of the mucin gene MUC2 [3, 4]. Conversely, bacteria such as Staphylococcus aureus [5] and $P$. aeruginosa [6] are able to bind to mucins. Therefore, mucus overproduction and bacterial infection can support each other. However, the pathogenesis of $\mathrm{CF}$ mucus hypersecretion has not yet been fully elucidated.

Recently, cytokines, such as interleukin (IL)-9, have been reported to play an important role in the pathogenesis of mucus hypersecretion in various lung diseases. A cytokine produced by T-lymphocytes, IL-9, has been implicated in the pathogenesis of airway hyperresponsiveness and mucus hypersecretion in asthma [7-10]. It plays a dominant role in MUC2 and MUC5AC overproduction both in vitro and in vivo $[8,9]$, and has been found to upregulate a calciumactivated chloride channel (CLCA) within airways [10]. Murine mCLCA3 is expressed in the lungs of IL-9 transgenic mice, and intratracheal IL-9 instillations in the lungs of control mice dramatically increase mCLCA3 expression [10]. Subsequently, ectopic expression of either mCLCA3 or its

For editorial comments see page 797. human homologue hCLCA1 in the human mucoepidermoid cell line NCI-H292 results in the upregulation of MUC5AC [11]. The human calcium-activated chloride channel hCLCA1 has been shown to be closely related to mucus production in bronchial epithelium of patients with asthma [12]. Moreover, increased expression of hCLCA1 has recently been demonstrated in the nasal and sinus mucosa of $\mathrm{CF}$ patients [13]. Therefore, in CF, hCLCA1 may contribute at least in part to mucus overproduction, similar to its role in asthma.

In the present study, the authors sought to examine the expression of IL-9, IL-9 receptor (IL-9R), and hCLCA1 in the bronchial mucosa of $\mathrm{CF}$ patients in comparison to normal control subjects, and to demonstrate their relationship with mucus production. The current authors propose that mucus hypersecretion in the bronchial epithelium of patients with $\mathrm{CF}$ is associated with increased expression of IL-9, IL-9R, and hCLCA1.

\section{Methods}

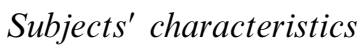

The present study was approved by the ethics committees of all participating institutions. Endoscopic biopsy samples of 
bronchial mucosa were obtained from $10 \mathrm{CF}$ patients and six healthy control subjects. Each patient and control had three to four mucosal biopsies taken from the subcarinae of the lower lobes or the middle lobe. Characteristics for patient and control groups are summarised in table $1 . \mathrm{CF}$ patients were in stable condition (free of exacerbation for $\geqslant 6$ months) without any signs of exacerbation at the time of biopsy. Seven CF patients were chronically infected with $P$. aeruginosa. Patients received inhaled antibiotics, $\beta_{2}$-agonists, pancreatic enzyme substitution and vitamins. No patient was treated with intravenous antibiotics at the time of biopsy. All patients and controls were nonsmokers.

\section{Tissue preparation}

For immunocytochemistry, biopsy specimens were immediately snap-frozen in isopentane cooled in liquid nitrogen. For in situ hybridisation (ISH), biopsy specimens were immediately fixed in $4 \%$ paraformaldehyde/PBS for $2 \mathrm{~h}$, washed three times in $15 \% \mathrm{PBS} /$ sucrose, embedded in optimal cutting temperature (Tissue-Tek, Sakura Finetek, CA, USA) and then snap-frozen in isopentane cooled in liquid nitrogen. Cryostat sections $10-\mu \mathrm{m}$ thick were cut onto $0.1 \%$ poly-Llysine-coated slides, baked in an oven at $37^{\circ} \mathrm{C}$ overnight and then stored at $-80^{\circ} \mathrm{C}$ until further use.

\section{Probe preparation}

Sulphur $35\left(\mathrm{~S}^{35}\right)$-labelled complementary RNA probe coding for the hCLCA1 mRNA was prepared from cDNA as previously described [14]. Briefly, cDNA was inserted into expression vectors, linearised and transcribed in vitro in the presence of $\mathrm{S}^{35}$-UTP, T7 and SP6 polymerase in either direction to produce both anti-sense (complementary) and sense probes (identical to mRNA).

\section{In situ hybridisation}

Sections of bronchial tissue were processed for ISH to identify hCLCA1 mRNA as previously described [13]. In short, after permeabilisation, sections were prehybridised with $50 \%$ formamide in $2 \times$ standard sodium citrate for $15 \mathrm{~min}$ at $37^{\circ} \mathrm{C}$. Hybridisation was carried out overnight at $42^{\circ} \mathrm{C}$ with the appropriate hybridisation mixture containing either the $\mathrm{S}^{35}$-labelled sense or anti-sense probe $\left(0.75 \times 10^{6} \mathrm{cpm} \cdot \mathrm{slide}^{-1}\right)$. Post-hybridisation involved a series of washes, performed with decreasing concentrations of saline-sodium citrate buffer at $42^{\circ} \mathrm{C}$. Samples were washed with ribonuclease solution for $20 \mathrm{~min}$ at $42^{\circ} \mathrm{C}$ to remove any unbound RNA probes. Hybridisation signal was detected with standard autoradiography. All experiments were done in triplicate.

Table 1.-Clinical characteristics of the study population

\begin{tabular}{lccc}
\hline & $\mathrm{CF}$ & Control & p-value \\
\hline Subjects n & 10 & 6 & \\
Age yrs & $32.6 \pm 4.4$ & $35.8 \pm 4.8$ & NS \\
Sex M:F & $4: 6$ & $5: 1$ & \\
FEV1\% pred & $57.6 \pm 7.4$ & $104.2 \pm 5.5$ & $<0.05^{\#}$ \\
\hline
\end{tabular}

Data are presented as mean \pm SEM. CF: cystic fibrosis; M: male; F: female; FEV1 \% pred: forced expiratory volume in one second $\%$ predicted. ${ }^{\#}$ : CF versus control; NS: nonsignificant.

\section{Histochemistry and immunohistochemistry}

Bronchial sections were fixed with 4\% paraformaldehyde and then stained with periodic acid-Schiff (PAS) to identify mucus glycoconjugates and mucus-producing goblet cells. To detect T-cells, neutrophils, IL-9, IL-9R and hCLCA1, immunostaining was performed with use of the alkaline phosphatase-anti-alkaline phosphatase (APAAP) technique as previously described [15]. The antibodies used were antiCD3 (pan T-lymphocyte; Dako, Mississauga, ON, Canada), anti-elastase (neutrophils; Dako), anti-IL-9 (R\&D Systems, Minneapolis, MN, USA), anti-IL-9R (R\&D Systems) and anti-hCLCA1 (a gift from Genaera Corporation, Plymouth Meeting, PA, USA). Briefly, sections were incubated with primary antibodies at $4^{\circ} \mathrm{C}$ overnight, washed and then treated with rabbit anti-mouse antibody or rabbit anti-goat antibody (for IL-9) for $30 \mathrm{~min}$, at room temperature. The antibodyantigen complex was developed with the APAAP complex or biotin-streptavidin complex (for IL-9) and Fast Red (Sigma Chemical Company, Weinham, Germany). At least two slides were stained for each patient and control for each marker.

\section{Combined in situ hybridisation and histochemistry- immunocytochemistry}

To study the association between hCLCA1 expression and IL-9R, a radiolabelled cRNA probe coding for hCLCA1 mRNA with IL-9R antibody was simultaneously applied, as previously described [14]. For the colocalisation of hCLCA1 to mucus-producing cells, sections were first stained with PAS, and subsequently hybridised with $S^{35}$-labelled probes coding for hCLCA1. All experiments were done in duplicate.

\section{Quantification}

All slides were read blinded (coded) and positive cells were counted. Epithelial cells ( $\geqslant 200$ cells) were counted and cells positive for PAS staining, cells positive for either IL-9R or hCLCA1, and those positive for hCLCA1 mRNA signals were individually expressed as a percentage of total epithelial cells. IL-9-, CD3-, and elastase-immunoreactive cells in the submucosa were expressed as the number of positive cells $\cdot \mathrm{mm}^{2}$ of submucosa. Each slide was counted by two experienced observers. The within-observer coefficient of variation for repeated measures was $<5 \%$.

\section{Statistical analysis}

The difference in the number of cells expressing hCLCA1, IL-9 and IL-9R, as well as staining for mucin (PAS), were compared with the nonparametric Kruskal-Wallis test. Statistically significant differences between groups were subsequently analysed with the Mann-Whitney U-test. Correlation coefficients were calculated from the Pearson moment coefficient and were corrected for multiple comparisons using the Bonferroni correction factor. Results are expressed as mean \pm SEM and a $p$-value $<0.05$ was considered statistically significant.

\section{Results}

Neutrophils and T-cells in the bronchial mucosa of patients and controls

CF patients showed significantly higher numbers of neutrophils in the bronchial mucosa $\left(140.4 \pm 29.0 \cdot \mathrm{mm}^{2}\right)$ 
compared to control subjects $\left(32.0 \pm 10.1 \cdot \mathrm{mm}^{2} ; \mathrm{p}<0.05\right)$. The number of T-lymphocytes in CF patients $\left(263.0 \pm 42.9 \cdot \mathrm{mm}^{2}\right)$ was not significantly higher in comparison to control subjects $\left(153.0 \pm 20.4 \cdot \mathrm{mm}^{2} ; \mathrm{p}>0.05\right)$.

Expression of $I L-9, I L-9 R$ and $h C L C A 1$, and periodic acid-Schiff staining

Immunostaining showed significantly higher numbers $(\mathrm{p}<0.05)$ of IL-9-positive cells in the submucosa of CF patients $\left(46.5 \pm 6.8 \cdot \mathrm{mm}^{2}\right)$ compared to control subjects $\left(7.0 \pm 2.5 \cdot \mathrm{mm}^{2}\right)$. More epithelial cells $(\mathrm{p}<0.05)$ in CF patients expressed IL-9R $(71.3 \pm 7.5 \%)$ and hCLCA1 (82.5 $\pm 7.5 \%$; figs $1 \mathrm{~b}$ and 2$)$ compared to those of control individuals (IL-9R: $17.5 \pm 3.1 \%$; hCLCA1: $22.9 \pm 9.4 \%$; figs $1 \mathrm{a}$ and 2 ). Expression of hCLCA1 mRNA in epithelial cells was similar to hCLCA1 protein expression in $\mathrm{CF}$ patients and control subjects (fig. 2).

There was a notably higher number of PAS-positive staining epithelial cells in CF patients $(71.3 \pm 6.9 \%)$ compared to control subjects $(25.0 \pm 12.9 \% ; \mathrm{p}<0.05$; fig. 2). PAS-positive epithelium was also detected in submucosal glands of $\mathrm{CF}$ patients.
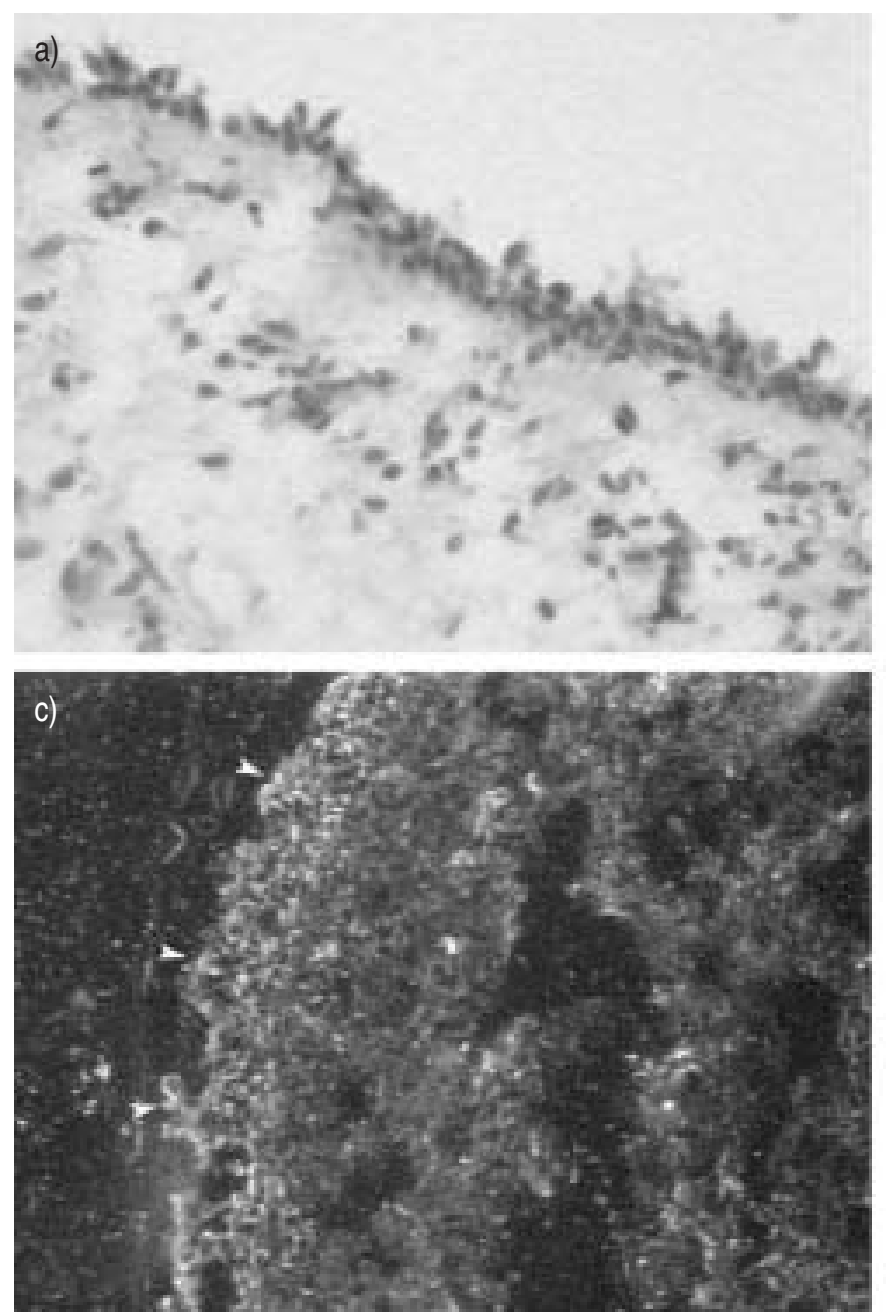

Correlation of $I L-9$ and $I L-9 R$ with expression of hCLCA1 $\mathrm{mRNA}$ and protein in the epithelium

In both $\mathrm{CF}$ patients and control subjects, a positive correlation was found between IL-9R- and IL-9-positive cells $(\mathrm{r}=0.63 ; \mathrm{p}<0.05$; fig. $3 \mathrm{a})$. A positive correlation between IL-9R expression in the epithelium and hCLCA1 mRNA $(\mathrm{r}=0.72 ; \mathrm{p}<0.05)$ and $\mathrm{hCLCA} 1$ protein expression $(\mathrm{r}=0.82$; $p<0.05$; fig. $3 b$ ) was observed. The percentage of mucuscontaining PAS-positive epithelial cells was correlated with the percentage of hCLCA1 mRNA-positive cells ( $\mathrm{r}=0.76$; $\mathrm{p}<0.05)$, with hCLCA1 protein-positive cells $(\mathrm{r}=0.76$; $\mathrm{p}<0.05$; fig. $3 \mathrm{c})$ and with the percentage of IL-9R-positive epithelial cells ( $\mathrm{r}=0.63$; $\mathrm{p}<0.05$; fig. $3 \mathrm{~d}$ ).

\section{Colocalisation of $I L-9 R$ and PAS staining with hCLCA1 mRNA expression in CF patients}

IL-9R expression was colocalised with hCLCA1 mRNA expression in the epithelium of CF patients (fig. 1c). PAS-positive epithelial cells expressed hCLCA1 mRNA (fig. 1d). Furthermore, colocalisation of PAS-positive staining and hCLCA1 mRNA expression was also observed in submucosal glands.

b)
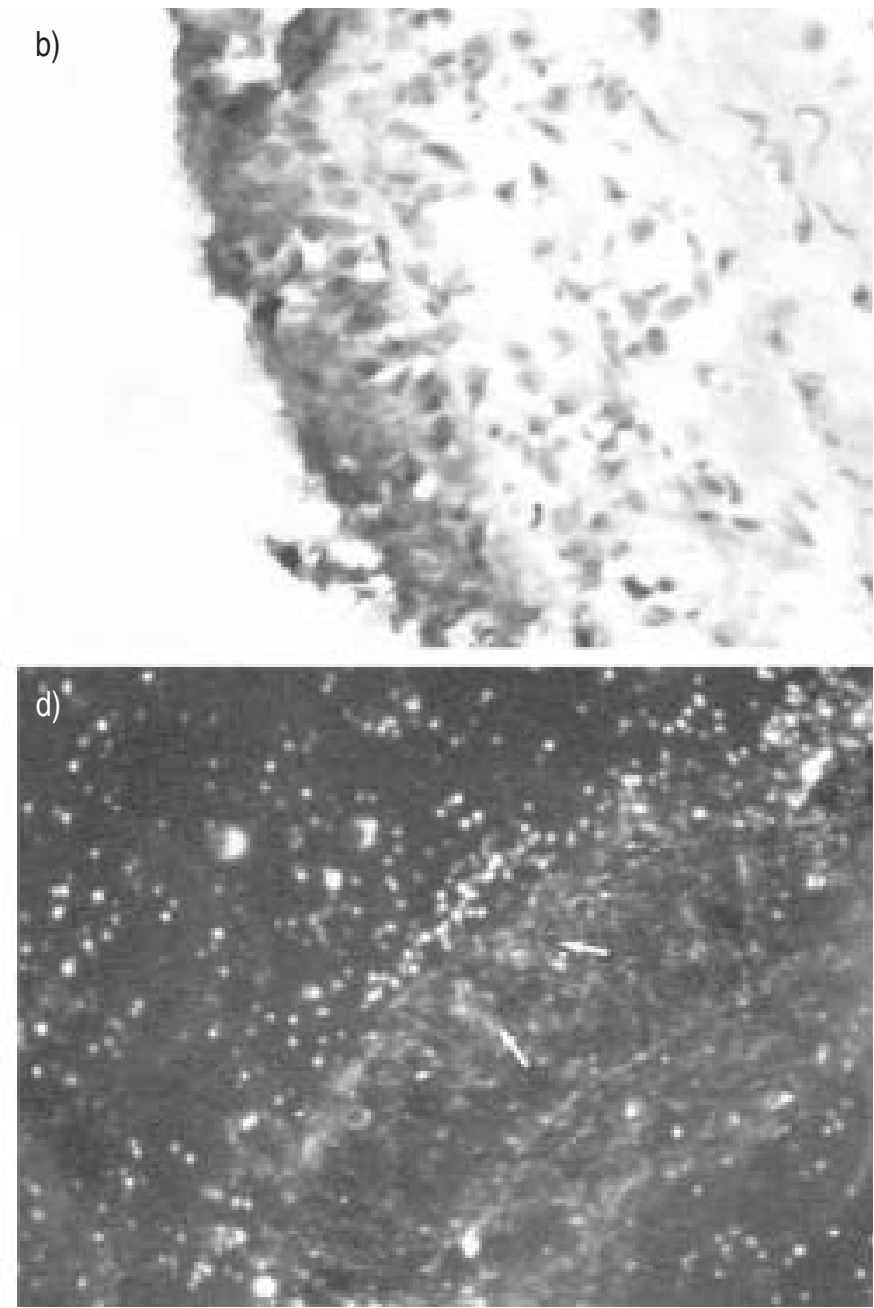

Fig. 1. - Representative examples of the human calcium-activated chloride channel (hCLCA1) immunostaining in a control subject (a) and a cystic fibrosis (CF) patient (b). Epithelial cells expressing hCLCA1 stain red. Colocalisation of hCLCA1 mRNA and interleukin-9 receptor (IL9R) expression (c) or periodic acid-Schiff (PAS)-positive staining epithelium (d) in a CF patient. Arrow heads indicate epithelial cells expressing IL-9R (red) and hCLCA1 (white) (c). Arrows indicate epithelial cells staining positive for mucous glycoproteins (PAS; red) and hCLCA1 (white) (d). 


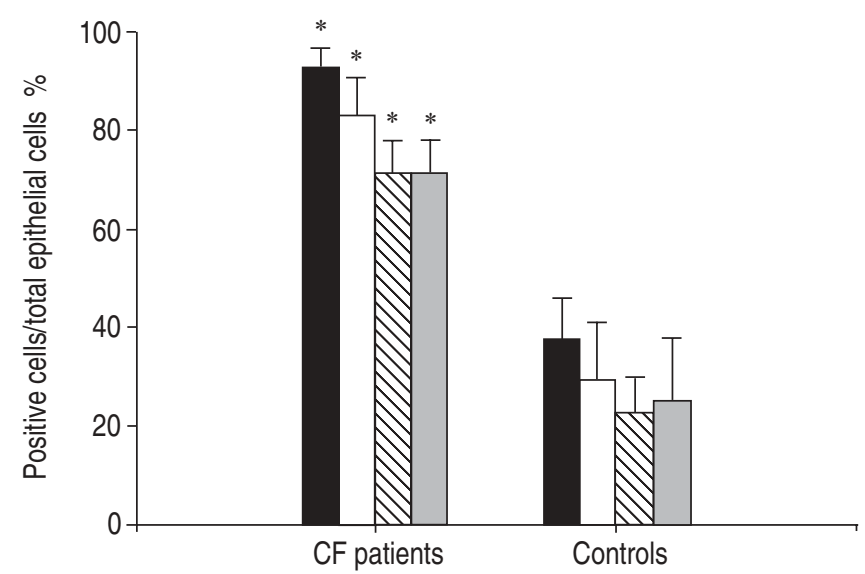

Fig. 2. - Expression of the human calcium-activated chloride channel (hCLCA1; $\mathbf{\square}$ : mRNA; $\square$ : protein), interleukin-9 receptor (IL-9R; $\mathbb{\nabla})$ and periodic acid-Schiff (PAS; $)$-positive cells in the bronchial epithelium of cystic fibrosis (CF) patients $(n=10)$ compared to that seen in healthy control subjects $(n=6)$. Results are expressed as a mean \pm SEM of positive cells/total epithelial cells. *: $\mathrm{p}<0.05$ versus control subjects.

\section{Discussion}

The present study has shown, for the first time, an increased expression of IL-9, its receptor IL-9R and hCLCA1 in CF
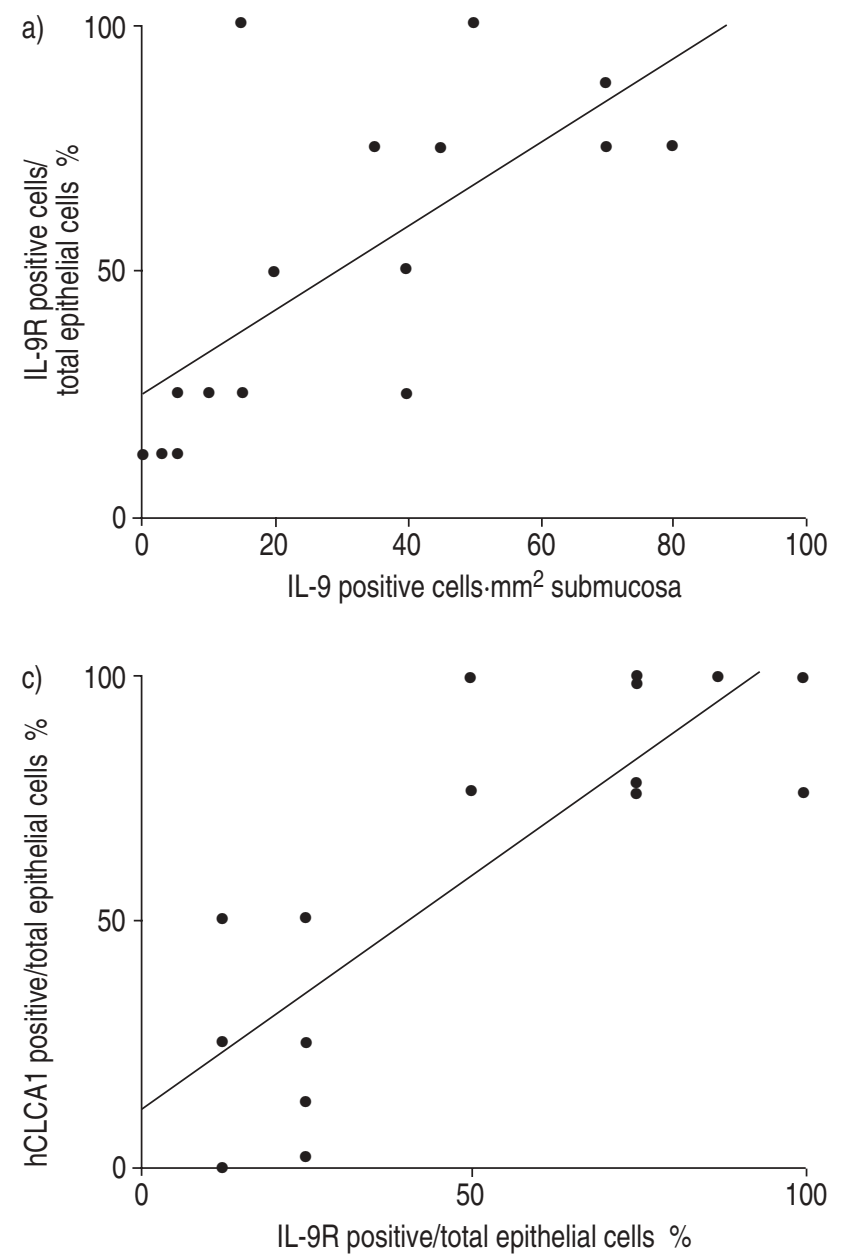

bronchial mucosa. It further reports a close association between IL-9R-positive cells with IL-9-positive cells and hCLCA1-positive cells, as well as between PAS-positive cells with IL-9R-positive and hCLCA1-positive cells. Combined ISH and histochemistry-immunocytochemistry showed colocalisation of hCLCA1 with IL-9R- and PAS-positive cells.

Previous reports have demonstrated a close correlation between IL-9, IL-9R and hCLCA1 in human asthmatics and in animal models $[8,12]$. Furthermore, IL-9-induced upregulation of hCLCA1 has been linked to increased production of gel-forming mucins in vitro $[11,12]$. Thus, the findings of the current study agree with previous data showing increased expression of IL-9, IL-9R and hCLCA1 present in CF bronchial mucosa. The results of the current study support the notion that mucus overproduction in $\mathrm{CF}$ is, at least in part, due to IL-9-induced upregulation of hCLCA1 [13].

Alternative chloride channels, such as the voltage-gated chloride channel, CIC-2, have been recommended as possible candidates to replace CFTR function and restore chloride currents [16]. From the results of the present study it seems that hCLCA1 may contribute to calcium-activated chloride currents that have been measured in CF epithelia [17, 18]. However, upregulation of this channel was associated with mucus overexpression, and hCLCA1 may, therefore, not be the ideal candidate to replace $\mathrm{CF}$ transmembrane conductance regulator function.

In conclusion, increased expression of the interleukin-9-induced
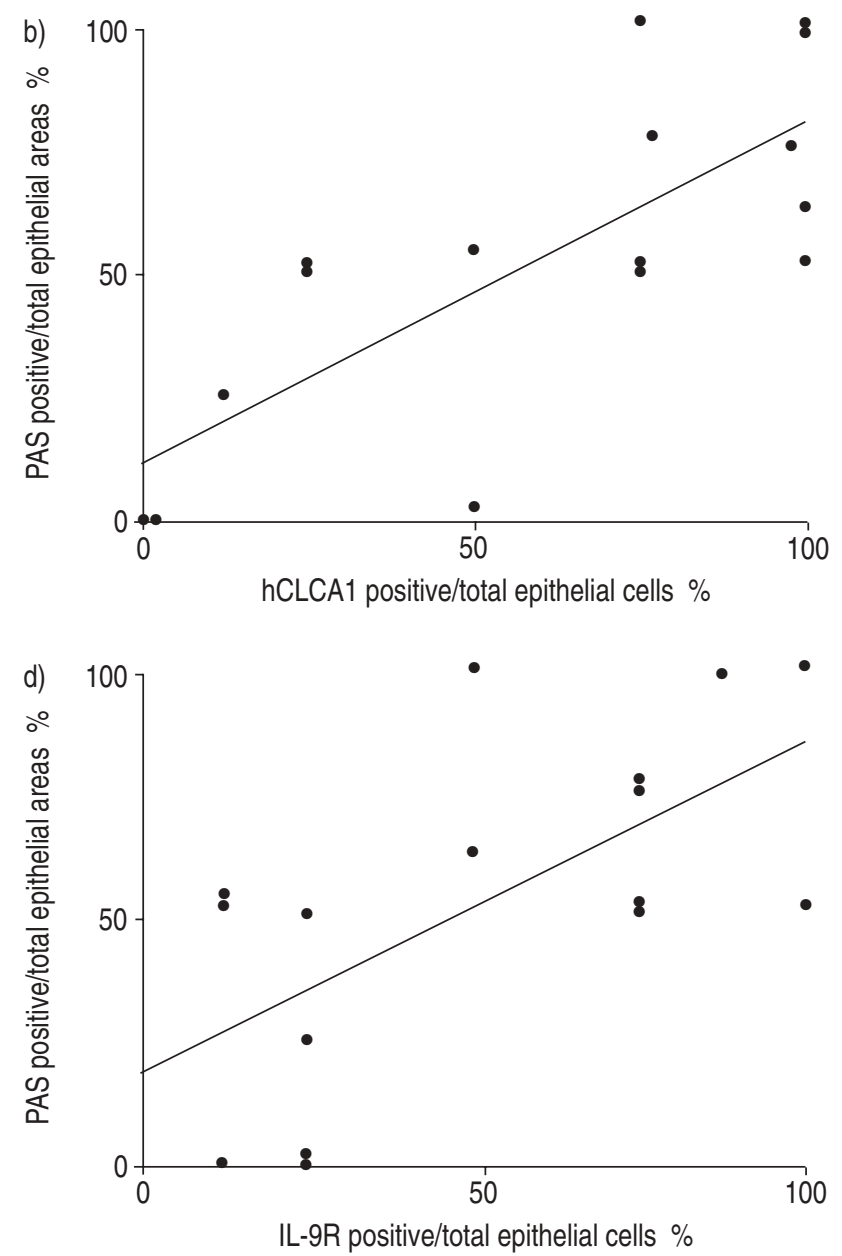

Fig. 3. - Correlation between interleukin-9 receptor (IL-9R)-positive cells and a) IL-9-(r=0.63) or c) human calcium-activated chloride channel (hCLCA1)-positive cells ( $\mathrm{r}=0.72$ ) in both cystic fibrosis patients and healthy control subjects. Correlations between periodic acid-Schiff (PAS)positive cells and b) hCLCA1- $(\mathrm{r}=0.76)$ or $\mathrm{d}) \mathrm{IL}-9 \mathrm{R}$-positive cells $(\mathrm{r}=0.63)$ are also shown. 
calcium-activated chloride channel, hCLCA1, is associated with mucus overproduction. Accordingly, it has been shown that cytokine-induced mucus production is indeed present in cystic fibrosis airways. However, it has to be taken into account that the sample size in this study was small (10 patients). Therefore, the presented data have to be interpreted with care concerning generalisations. Further studies are warranted in order to examine whether inhibition of this channel might offer a new treatment option to reduce mucus hypersecretion in cystic fibrosis.

\section{References}

1. Breuer R, Christensen TG, Lucey EC, Stone PJ, Snider GL. Quantitative study of secretory cell metaplasia induced by human neutrophil elastase in the larger bronchi of hamsters. J Lab Clin Med 1985; 105: 635-640.

2. Voynow JA, Rosenthal Yuong L, et al. Neutrophil elastase increases MUC5AC mRNA and protein expression in respiratory epithelial cells. Am J Physiol 1999; 276: L835L843.

3. Li JD, Dohrman AF, Gallup M, et al. Transcriptional activation of mucin by Pseudomonas aeruginosa lipopolysaccharide in the pathogenesis of cystic fibrosis lung disease. Proc Natl Acad Sci USA 1997; 94: 967-972.

4. Li JD, Feng W, Gallup M, et al. Activation of NF- $\kappa$ B via a Src-dependent Ras-MAPK-pp90rsk pathway is required for Pseudomonas aeruginosa-induced mucin overproduction in epithelial cells. Proc Natl Acad Sci USA 1998; 95: 5718-5723.

5. Thomas VL, Sanford BA, Ramsay MA. Calcium- and mucin-binding proteins of staphylococci. J Gen Microbiol 1993; 139: 623-629.

6. Vishwanath S, Ramphal R. Adherence of Pseudomonas aeruginosa to human tracheobronchial mucin. Infect Immun 1984; 45: 197-202.

7. Nicolaides NC, Holroyd KJ, Ewart SL, et al. IL-9: a candidate gene for asthma. Proc Natl Acad Sci USA 1997; 94: $13175-13180$
8. Louahed J, Toda M, Jen J, et al. Interleukin-9 upregulates mucus expression in the airways. Am J Respir Cell Mol Biol 2000; 22: 649-656.

9. Longphre M, Li D, Gallup M, et al. Allergen-induced IL-9 directly stimulates mucin transcription in epithelial cells. $J$ Clin Invest 1999; 104: 1375-1382.

10. Zhou Y, Dong Q, Louahed J, et al. Characterization of a calcium-activated chloride channel as a shared target of Th2 cytokine pathways and its potential involvement in asthma. Am J Respir Cell Mol Biol 2001; 25: 486-491.

11. Nakanishi A, Morita S, Iwashita $\mathrm{H}$, et al. Role of gob-5 in mucus overproduction and airway hyperresponsiveness in asthma. Proc Natl Acad Sci USA 2001; 98: 5175-5180.

12. Toda M, Tulic MK, Levitt RC, Hamid Q. A calciumactivated chloride channel (hCLCA1) is strongly related to IL-9 expression and mucus production in bronchial epithelium of patients with asthma. J Allergy Clin Immunol 2002; 109: 246-250.

13. Hauber HP, Manoukian JJ, Nguyen LHP, et al. Increased expression of interleukin-9, interleukin-9 receptor and the calcium-activated chloride channel hCLCA1 in the upper airways of patients with cystic fibrosis. Laryngoscope 2003; 113: 1037-1042.

14. Hamid Q, Wharton J, Terenghi G, et al. Localization of atrial natriuretic peptide mRNA and immunoreactivity in the rat heart and human appendage. Proc Natl Acad Sci USA 1987; 84: 6760-6764.

15. Giaid A, Michel RP, Stewart DJ, Sheppard M, Corrin B, Hamid Q. Expression of endothelin-1 in lungs of patients with cryptogenic fibrosing alveolitis. Lancet 1993; 341: 15501554.

16. Schwiebert EM, Cid-Soto LP, Stafford D, et al. Analysis of ClC-2 channels as an alternative pathway for chloride conduction in cystic fibrosis airway cells. Proc Natl Acad Sci USA 1998; 95: 3879-3884.

17. Quinton PM. Cystic fibrosis: a disease in electrolyte transport. FASEB J 1990; 4: 2709-2717.

18. Welsh MJ. Abnormal regulation of ion channels in cystic fibrosis epithelia. FASEB J 1990; 4: 2718-2725. 